\title{
Article \\ Elephant Endotheliotropic Herpesvirus Is Omnipresent in Elephants in European Zoos and an Asian Elephant Range Country
}

\author{
Tabitha E. Hoornweg 1,2,*, Willem Schaftenaar ${ }^{3}$, Gilles Maurer 4,5 ${ }^{(\mathbb{D}}$, Petra B. van den Doel ${ }^{6}$, \\ Fieke M. Molenaar ${ }^{7}$, Alexandre Chamouard-Galante ${ }^{8}$, Francis Vercammen ${ }^{9}$, Victor P. M. G. Rutten ${ }^{2,10}{ }^{\mathbb{D}}$ and
} Cornelis A. M. de Haan $1, *(\mathbb{D})$

Citation: Hoornweg, T.E.; Schaftenaar, W.; Maurer, G.; van den Doel, P.B.; Molenaar, F.M.;

Chamouard-Galante, A.; Vercammen,

F.; Rutten, V.P.M.G.; de Haan, C.A.M.

Elephant Endotheliotropic

Herpesvirus Is Omnipresent in

Elephants in European Zoos and an

Asian Elephant Range Country.

Viruses 2021, 13, 283. https://

doi.org/10.3390/v13020283

Academic Editor:

Shafiqul Chowdhury

Received: 22 January 2021

Accepted: 6 February 2021

Published: 11 February 2021

Publisher's Note: MDPI stays neutral with regard to jurisdictional claims in published maps and institutional affiliations.

Copyright: (c) 2021 by the authors. Licensee MDPI, Basel, Switzerland. This article is an open access article distributed under the terms and conditions of the Creative Commons Attribution (CC BY) license (https:/ / creativecommons.org/licenses/by/ $4.0 /)$.
1 Section Virology, Division Infectious Diseases and Immunology, Department of Biomolecular Health Sciences, Faculty of Veterinary Medicine, Utrecht University, 3584 CL Utrecht, The Netherlands

2 Section Immunology, Division Infectious Diseases and Immunology, Department of Biomolecular Health Sciences, Faculty of Veterinary Medicine, Utrecht University, 3584 CL Utrecht, The Netherlands; v.rutten@uu.nl

3 Veterinary Advisor EAZA Elephant TAG, Rotterdam Zoo, 3041 JG Rotterdam, The Netherlands; w.schaftenaar@diergaardeblijdorp.nl

4 Center for Functional and Evolutionary Ecology (CEFE), Univ. Montpellier, CNRS, EPHE, IRD, Univ. Paul Valéry Montpellier 3, 34090 Montpellier, France; gilles.maurer@cefe.cnrs.fr

5 Zooparc de Beauval \& Beauval Nature, 41110 Saint-Aignan, France

6 ViroScience Lab, Erasmus Medical Center, 3015 CN Rotterdam, The Netherlands; p.vandendoel@erasmusmc.nl

7 Zoological Society of London, ZSL Whipsnade Zoo, Dunstable LU6 2LF, UK; Fieke.Molenaar@zsl.org

8 École Nationale Vétérinaire d'Alfort, 94700 Maisons-Alfort, France; alexandre.galante@vet-alfort.fr

9 Antwerp Zoo Centre for Research and Conservation, Antwerp Zoo Society, 2018 Antwerp, Belgium; Francis.Vercammen@kmda.org

10 Department of Veterinary Tropical Diseases, Faculty of Veterinary Science, University of Pretoria, Private Bag X04, Onderstepoort 0110, South Africa

* Correspondence: T.E.Hoornweg@uu.nl (T.E.H.); C.A.M.deHaan@uu.nl (C.A.M.d.H.)

\begin{abstract}
Elephant endotheliotropic herpesviruses (EEHVs) may cause acute, often lethal, hemorrhagic disease (EEHV-HD) in young elephants. Prevalence of EEHV in different elephant populations is still largely unknown. In order to improve diagnostic tools for the detection of EEHV infections and to obtain insight into its spread among elephants, we developed novel ELISAs based on EEHV1A $\mathrm{gB}$ and $\mathrm{gH} / \mathrm{gL}$. Performance of the ELISAs was assessed using sera from 41 European zoo elephants and 69 semi-captive elephants from Laos, one of the Asian elephant range countries. Sera from all (sub)adult animals tested ( $\geq 5$ years of age) showed high reactivity with both $\mathrm{gB}$ and $\mathrm{gH} / \mathrm{gL}$, indicating that EEHV prevalence has been highly underestimated so far. Reactivity towards the antigens was generally lower for sera of juvenile animals ( $1>5$ years). Only one (juvenile) animal, which was sampled directly after succumbing to EEHV-HD, was found to be seronegative for EEHV. The two other EEHV-HD cases tested showed low antibody levels, suggesting that all three cases died upon a primary EEHV infection. In conclusion, our study suggests that essentially all (semi-)captive (sub)adult elephants in European zoos and in Laos carry EEHV, and that young elephants with low antibody levels are at risk of dying from EEHV-HD.
\end{abstract}

Keywords: EEHV; herpesviruses; elephant; immunoserology; gB; gH/gL

\section{Introduction}

Elephant endotheliotropic herpesviruses (EEHVs) are responsible for a significant mortality rate observed in captive Asian elephants (Elephas maximus), and increasingly in African elephants (Loxodonta africana) in Western zoos [1-3]. Over the last decades, nearly $20 \%$ of all Asian elephant calves born in Western zoos succumbed to EEHV-HD [1]. 
Furthermore, multiple reports showed that the disease affects both captive and wild elephants in the Asian elephant range countries [4-6]. How widespread the virus is, and its prevalence in free-living populations, has yet to be established.

EEHVs are a group of evolutionary divergent herpesviruses, of which eight types have been identified so far [3]. Four (sub)types (EEHV-1A, $-1 \mathrm{~B},-4$, and -5 ) naturally infect Asian elephants, while the other types (EEHV-2, -3, -6, and -7) infect African elephants. Like other members of the herpesvirus family, EEHVs cause latent infections in their host species. Healthy elephants can intermittently shed one or multiple EEHV subtypes as part of the natural infection cycle [7]. It has been suggested that primary infections of young elephants, commonly aged between 1 to 8 years, although often subclinical, may lead to acute, often lethal EEHV-Hemorrhagic Disease (EEHV-HD), which is particularly observed for EEHV-1A in Asian elephants [3,8].

Currently, both the assessment of EEHV infections of individual animals and the assessment of herd prevalence are largely performed using PCR on blood samples $[5,6,9]$. Latent EEHV infections can only be detected upon reactivation, hence detection of EEHV prevalence by PCR requires longitudinal sampling over an extended period of time. Since PCR is relatively costly, and requires specialized equipment and trained personnel, the availability of this technique is limited in zoo laboratories and many elephant range countries [10]. The virus-specific immune response is expected to remain present for the lifetime of the host [11]. Therefore, serology would be the most convenient and cost effective method to assess EEHV prevalence in elephant populations.

To date, two different serological assays have been described. Van den Doel et al., (2015) designed an EEHV-specific ELISA with E. coli-expressed EEHV1A glycoprotein B $(\mathrm{gB})$ as the antigen [12]. This assay has been used to test two large cohorts of elephant sera and showed that $37 \%$ of elephants from Western zoos [12] and $42 \%$ of captive elephants in Thailand [13] were seropositive for EEHV. Although it was shown that EEHV infections were relatively wide-spread, $24 \%$ of the elephants with PCR-confirmed EEHV infection were designated EEHV seronegative in this assay [12], indicating that this assay probably underestimates EEHV seropositivity. Recently, a second serological assay was described by Fuery et al. [8], who used four different EEHV proteins genetically fused to luciferase and expressed in mammalian cells as antigenic fractions. It was shown that $82 \%$ of all elephants tested ( $n=24$, from four different North American zoos), including $100 \%$ of the adult animals ( $\geq 15$ years of age; $n=10)$, were EEHV seropositive [8].

The herpesvirus $\mathrm{gB}$, glycoprotein $\mathrm{H}(\mathrm{gH})$ and glycoprotein $\mathrm{L}(\mathrm{gL})$ are conserved between all herpesviruses and essential for host cell entry. The fusion protein gB naturally forms a homotrimer [14]. A heterodimer of $\mathrm{gH}$ and $\mathrm{gL}$ acts as an activator of $\mathrm{gB}$ and may function in receptor binding $[15,16]$. Both $\mathrm{gB}$ and the $\mathrm{gH} / \mathrm{gL}$ dimer are important targets of the herpesvirus-specific humoral immune response [17-20], hence interesting for use in EEHV-specific serological assays. Although expression of recombinant EEHV gB has been reported [8,12], purification has only been achieved from bacterial cultures. Expression of recombinant EEHV $\mathrm{gH} / \mathrm{gL}$ has not been described thus far.

The current study aimed to improve diagnostic tools for EEHV infection in elephants, thereby focusing on $\mathrm{gB}$ and $\mathrm{gH} / \mathrm{gL}$ as antigens, and, by use of these tools, to obtain novel insight into the spread of EEHV among elephants. We describe the successful purification of secreted recombinant EEHV1A $\mathrm{gB}$ and $\mathrm{gH} / \mathrm{gL}$ produced in mammalian cells. Both $\mathrm{gB}$ and $\mathrm{gH} / \mathrm{gL}$ were strongly recognized by antibodies present in elephant sera, indicating their value as antigens in EEHV-specific ELISAs. We subsequently showed that all subadult (between 5 and 15 years of age) and adult elephants ( $\geq 15$ years of age), living under human care in either European zoos $(n=34)$ or an Asian elephant range country (Laos, $n=69$ ), were seropositive for EEHV. Furthermore, all three EEHV-HD cases tested had low or non-detectable EEHV-specific antibody titers, indicating that these animals experienced primary infections as previously suggested [8]. 


\section{Materials and Methods}

\subsection{Expression of Recombinant EEHV Proteins}

Codon-optimized cDNAs (Genscript Biotech, Leiden, The Netherlands) encoding EEHV1A gB (accession number AAN03667; residues 43-685), gH (accession number AGG16086; residues 30-706), and gL (accession number AGG16117; residues 57-304) were cloned into a pFRT expression plasmid (Thermo Fisher Scientific, Waltham, MA, USA) in frame with sequences encoding the Gaussia luciferase (Gluc) signal sequence and a C-terminal StrepTag (ST) or HisTag (HT) as depicted in Figure 1A. To increase expression levels, seven amino acid substitutions were introduced into the fusion loops (F126H, Y128T, and W209A) and the furin cleavage site (R432K, R433K, R434K, R436K) of the gB construct.

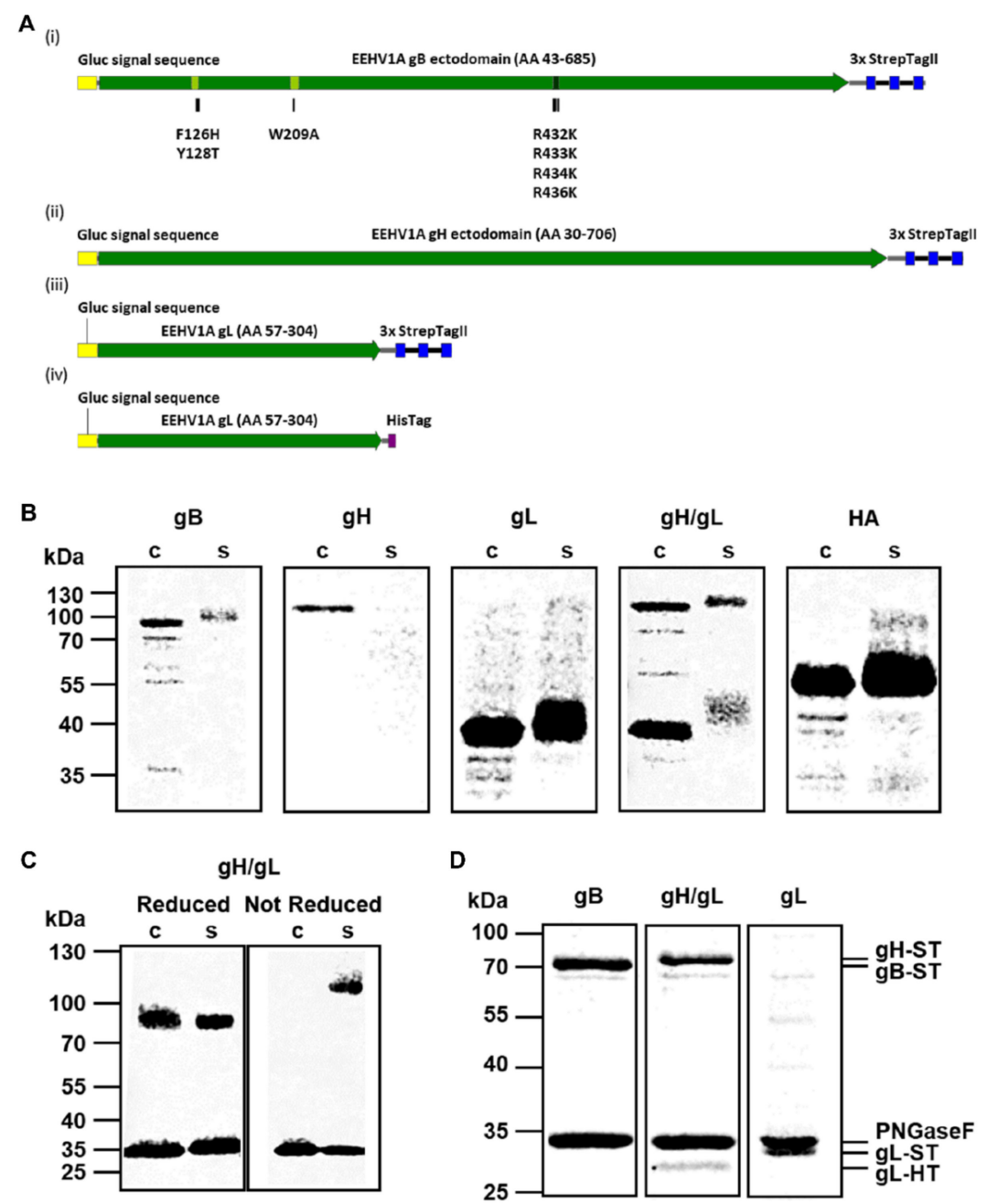

Figure 1. Production of recombinant EEHV1A gB, gH/gL and gL using the HEK293T expression system. (A) Schematic representation of the recombinant (i) gB-ST, (ii) gH-ST, (iii) gL-ST and (iv) gL-HT proteins. Amino acid mutations introduced into the two putative fusion loops (light green) and furin cleavage site (dark green) of $\mathrm{gB}$ are indicated as black bars. (B) Representative Western Blots showing the cell lysate (c) and secreted (s) fractions of recombinant EEHV1A gB, gH, gL, $\mathrm{gH} / \mathrm{gL}$ and the IAV HA control produced in HEK293T cells. (C) Western Blot of the cell lysate (c) and secreted (s) fractions harvested from a gH-ST/gL-ST co-transfection subjected to SDS-PAGE under reducing and non-reducing conditions. Proteins were deglycosylated by PNGaseF prior to electrophoresis. (D) Gelcode Blue-stained purified EEHV1A gB- ST, gH-ST/gL-HT and gL-ST. Samples were deglycosylated by PNGaseF prior to electrophoresis to facilitate analysis. Molecular mass markers are indicated on the left side of the gels. EEHV = Elephant endotheliotropic herpesvirus 
HEK293T cells (ATCC CRL-3216) were cultured in DMEM (Gibco, Thermo Fisher Scientific) supplemented with $10 \%$ Fetal Calf Serum (FCS; Bodinco, Alkmaar, The Netherlands), Penicillin (100 U/mL) and Streptomycin $(100 \mu \mathrm{g} / \mathrm{mL})$ (both from Lonza, Basel, Switzerland) at $37^{\circ} \mathrm{C}$ under $5 \% \mathrm{CO}_{2}$. Individual plasmids or a combination of the $\mathrm{gH}$ and gL expression plasmids (4:1 ratio) were transfected into HEK293T cells using polyethylenimine (PolySciences, Warrington, PA, USA) as described previously [21]. A pFRT expression plasmid encoding the Influenza A virus (IAV) Haemagglutinin (H1) ectodomain coupled to a C-terminal Strep-Tag was used as a control [22]. Five days post transfection cell culture media were harvested. Additionally the cells were lysed using Radioimmunoprecipitation assay (RIPA) buffer $(150 \mathrm{mM} \mathrm{NaCl}, 1 \%$ Triton $\mathrm{X}-100,0.5 \%$ sodium deoxycholate, $0.1 \%$ SDS, $50 \mathrm{mM}$ Tris, $\mathrm{pH} 8.0$ ) for $30 \mathrm{~min}$ at $4{ }^{\circ} \mathrm{C}$. Subsequently, cell culture media and lysates were centrifuged, supernatants were collected and subjected to sodium dodecyl sulfate-polyacrylamide gel electrophoresis (SDS-PAGE). When indicated, proteins were deglycosylated by PNGaseF (NEB, Ipswich, MA, USA) prior to gel electrophoresis. Proteins were transferred to a PVDF membrane using the Transblot Turbo System (BioRad), stained using a horseradish peroxidase (HRP)-conjugated monoclonal anti-StrepTag antibody (Iba, Goettingen, Germany) and detected by use of enhanced chemiluminescence (ECL) Western Blotting substrate (Pierce, Thermo Fisher Scientific) and the Odyssey imaging system (LI-COR, Lincoln, NE, USA).

For purification, cell culture media containing the secreted EEHV glycoproteins were cleared of debris by low speed centrifugation and proteins were purified using Strep-Tactin Sepharose beads (Iba). Purified proteins were subjected to quantitative densitometry of GelCode Blue-stained protein gels (Thermo Fisher Scientific) containing bovine serum albumin (BSA) standards. Signals were imaged and analyzed with an Odyssey imaging system (LI-COR).

\subsection{Sera}

Fifty serum samples of 41 individual elephants from 15 European zoos were used in this study. For most elephants (39/41), species, age at sampling and sex were known. For seven animals, samples were taken at different time points, referred to as longitudinal samples. For one animal, two different sample types (heparin blood and EDTA blood) were collected at the same time, referred to as paired samples. All blood samples were taken aseptically from the ear or leg vein by zoo veterinary staff and sera were sent to our institutes for diagnostic purposes. Additionally, 77 sera from (semi-)captive elephants from Laos, previously described by Lassausaie et al. [23], were tested. The vast majority of these elephants were released into the forest for three to six months a year, where they could roam freely and interact with their wild counterparts. All samples were drawn in 2012 and for the vast majority of samples $(72 / 77)$, sex and age at sampling were known. For both serum cohorts, elephants were classified in age groups according to Arivazhagan and Sukumar [24]; Elephants $<1$ year old are considered as babies, those between 1 and 5 years are juveniles, and those between 5 and 15 years respectively $\geq 15$ years as subadults and adults. Sera with high background values (OD-values $>1$ in the wells lacking antigen) were excluded from analysis ( $n=8$, all from Laotian elephant cohort). The rabbit sera specific for gB peptides $1-5$ used in this study were previously described by Van der Doel et al. [12] All sera were shipped cooled and stored at $-20{ }^{\circ} \mathrm{C}$ upon receipt.

\subsection{ELISAs}

Purified recombinant EEHV1A gB, gH/gL or gL (diluted in PBS; $100 \mu \mathrm{L} /$ well) were coated overnight on Nunc MaxiSorp high protein-binding capacity ELISA plates (Thermo Fisher Scientific). Subsequently, plates were washed three times with PBST (PBS $+0.05 \%$ Tween-20) and incubated with blocking buffer (PBS containing 0.1\% Tween 20 and 3\% BSA $[w / v]$ for $2 \mathrm{~h}$. Next, plates were washed (three times with PBST) and $100 \mu \mathrm{L}$ serum diluted in blocking buffer was added to the wells for $1 \mathrm{~h}$. Plates were washed (three times with PBST), and incubated with $100 \mu \mathrm{L}$ HRP-conjugated recombinant Protein A/G $(0.5 \mu \mathrm{g} / \mathrm{mL}$ 
diluted in blocking buffer; Pierce), previously reported to bind elephant IgG $[25,26]$, for $1 \mathrm{~h}$. After washing (three times with PBST), $100 \mu \mathrm{L} /$ well TMB Substrate (Surmodics, Eden Prairie, MN, USA) was added, plates were incubated for $10 \mathrm{~min}$ in the dark, and the reaction was stopped by adding $100 \mu \mathrm{L} 12.5 \% \mathrm{H}_{2} \mathrm{SO}_{4}$. Optical density (OD) was measured at $450 \mathrm{~nm}$ in an EL-808 ELISA reader (BioTEK, Winooski, VT, USA). For each sample, the antigen-specific signal (signal in wells containing antigen) and serum-specific background signal (signal in wells lacking antigen) were assessed simultaneously, and the $\triangle \mathrm{OD}$ value (OD value antigen coated well-OD value uncoated well) was reported. Sera were excluded from analysis if OD-values in the wells lacking antigen were $>1(n=8$, all from Laotian elephant cohort). Mean background OD was $0.14 \mathrm{SD} \pm 0.06$ and 0.46 $\mathrm{SD} \pm 0.44$ for of the included samples of the European zoo and the Laotian elephant cohorts, respectively, and $1.47 \mathrm{SD} \pm 0.63$ for the excluded samples. The optimal antigen concentration was tested by antigen dilution (range 40-1.25 ng/well) using five elephant sera and a no serum control. After establishment of the optimal antigen concentration, the optimal serum dilution was determined using serum dilution ranges (1:25-1:3200) of the same elephant sera. To compare performance of the novel assay with the existing EEHVspecific ELISA using gB expressed in E. coli as antigen [12], a subset of 21 randomly selected sera were tested in both assays. The 'bacterial' gB ELISA was performed as previously described [12]. Upon use of the rabbit anti-gB peptide sera to assess epitope accessibility in the novel 'mammalian' and the 'bacterial' gB ELISAs, HRPO-conjugated swine anti-rabbit $\operatorname{IgG}(1: 1000, \mathrm{DAKO})$ was used as the conjugate.

\section{Results}

\subsection{Production and Purification of Recombinant EEHV1A $g B, g H / g L$ and $g L$}

The DNA constructs for the production of soluble recombinant EEHV1A glycoproteins $\mathrm{gB}, \mathrm{gH}$, and $\mathrm{gL}$ were designed as described in the Materials and Methods. The resulting glycoproteins are schematically depicted in Figure 1A. For all EEHV glycoproteins, the native signal sequences were exchanged for the Gluc signal sequence, transmembrane and cytoplasmic regions ( $\mathrm{gB}$ and $\mathrm{gH}$ ) were removed, and a StrepTag (ST) or HisTag (HT) was added at the protein C-terminus. Upon transfection of the gB-ST, gH-ST, gL-ST constructs, and the IAV HA-ST control construct into HEK293T cells, production of proteins of the expected size was observed (Figure 1B cell lysate fractions and Table 1). Of these proteins, gB-ST, gL-ST, and HA-ST were secreted into the supernatant (Figure 1B secreted fractions), while no secretion of gH-ST could be observed. When EEHV1A gH and gL were co-expressed, intracellular production and secretion of both proteins was observed as expected (Figure 1B) [27-30].

Table 1. Predicted molecular weights of the protein constructs used in the study.

\begin{tabular}{cccc}
\hline Construct & Predicted MW (kDa) & $\begin{array}{c}\text { Predicted N-Linked } \\
\text { Glycosylation Sites }\end{array}$ & $\begin{array}{c}\text { Predicted MW, N-Linked } \\
\text { Glycosylation Included (kDa) }\end{array}$ \\
\hline gB-ST & 80.4 & 6 & 95.4 \\
gH-ST & 84.6 & 8 & 104.6 \\
gL-ST & 34.8 & 4 & 44.8 \\
gL-HT & 29.9 & 4 & 39.9 \\
gH-ST/gL-ST & 119.4 & $8 / 4$ & 149.4 \\
gH-ST/gL-HT & 114.5 & $8 / 4$ & 144.5 \\
IAV HA-ST & 42.5 & 4 & 52.5 \\
\hline
\end{tabular}

${ }^{a}$ Molecular weights (MWs) were predicted using the online expasy PI/Mw tool [31]; ${ }^{\mathrm{b}}$ The number of N-linked glycosylation sites were predicted using the NetNGlyc server [32]; ${ }^{\mathrm{c}}$ To estimate the MW of the glycosylated proteins, a MW of $2.5 \mathrm{kDa}$ was added for each predicted N-linked glycan.

Previous studies on HCMV revealed that $\mathrm{gH}$ and $\mathrm{gL}$ are covalently linked by disulfide bonds to form a dimer [33]. Amino acid alignments of the HCMV and EEHV gH or gL sequences indicated that the cysteines involved in the formation of these disulfide bonds are conserved between HCMV and EEHV (Supplementary Figure S1). To explore whether 
the EEHV1A gH/gL heterodimer is also linked by disulfide bonds, the cell lysate and secreted EEHV1A gH/gL fractions were subjected to SDS-PAGE under reducing and nonreducing conditions. Under reducing conditions, two individual protein bands representing $\mathrm{gH}(\sim 85 \mathrm{kDa})$ and $\mathrm{gL}(\sim 35 \mathrm{kDa})$ were visible in both fractions (Figure 1C; reducing gel). Under non-reducing conditions, monomeric gL remained visible in both fractions, while monomeric $\mathrm{gH}$ was not visible. Instead, a protein band of approximately $120 \mathrm{kDa}$ was observed in the secreted fraction, corresponding to the predicted molecular weight of the disulfide-linked $\mathrm{gH} / \mathrm{gL}$ heterodimer $(\sim 119 \mathrm{kDa})$ (Figure 1C; non-reducing gel).

After confirmation of secretion of $\mathrm{gB}, \mathrm{gL}$ and the $\mathrm{gH} / \mathrm{gL}$ dimer into the supernatant, secreted proteins were subjected to affinity purification by use of their StrepTag. To prevent copurification of the gL monomer with the $\mathrm{gH} / \mathrm{gL}$ heterodimer, the StrepTag in the gL construct was exchanged for a HisTag (Figure 1A (iv)). Figure 1D shows Gelcode Blue stained gels of the affinity purified gB-ST, gH-ST/gL-HT, and gL-ST fractions. Samples were treated with PNGaseF to remove $\mathrm{N}$-glycans in order to facilitate protein quantification. Clear protein bands of the expected molecular weights were visible in all three fractions with minor contamination. Copurification of gL-HT with gH-ST further supported the formation of stable $\mathrm{gH} / \mathrm{gL}$ heterodimers (Figure 1D). Intensity of Gelcode Blue staining showed that both proteins were present at equimolar concentrations, indicating that $\mathrm{gH}$ and $\mathrm{gL}$ interact in a 1:1 ratio.

\subsection{Development of EEHV-Specific ELISAs Using Purified EEHV1A $g B, g H / g L$, and $g L$ Proteins}

The recombinant EEHV1A proteins were used for development of ELISAs to detect EEHV-specific antibodies in elephant sera. To define the optimal antigen concentrations for measurement of antibody titers, we used five individual elephant sera that had been shown to differ to some extent in their reactivity with the EEHV proteins in preliminary experiments and a no serum control using dilution ranges of the different proteins produced. Four out of five elephant sera showed a clear dose-dependent response to the gB antigen (Figure 2A), while the serum of one elephant and the no serum control were virtually unreactive. The same four elephant sera showed a dose-dependent response to $\mathrm{gH} / \mathrm{gL}$ (Figure 2B), albeit lower than for $\mathrm{gB}$. Interestingly, none of the elephant sera were reactive towards gL (Figure $2 \mathrm{C}$ ).

For $\mathrm{gB}$ and $\mathrm{gH} / \mathrm{gL}$, we chose 5 respectively $40 \mathrm{ng} /$ well for the detection of EEHVspecific antibodies, as these resulted in a high signal-to-noise ratio, while minimizing the amount of antigen required. As no reactivity towards gL was observed under the present assay conditions and coating of higher concentrations was not feasible because of limited protein quantities available, the highest concentration tested (40 $\mathrm{ng} /$ well) was used in further optimization of the ELISA. To define the optimal serum concentrations to be used in the ELISAs, dilution ranges of the same five sera were tested in combination with the optimal antigen coating concentrations defined. Clear dilution-dependent responses were observed for gB (Figure 2D) and gH/gL (Figure 2E) for the same four sera that showed a dose-dependent response in the antigen dilution ranges, while the serum of one animal remained virtually unreactive at all dilutions tested. Again, none of the sera showed a response towards gL (Figure 2F). A serum dilution of 1:100 was considered optimal for further ELISA screening in this study as at this dilution high reactivity was combined with a large difference in reactivity between the different sera. 

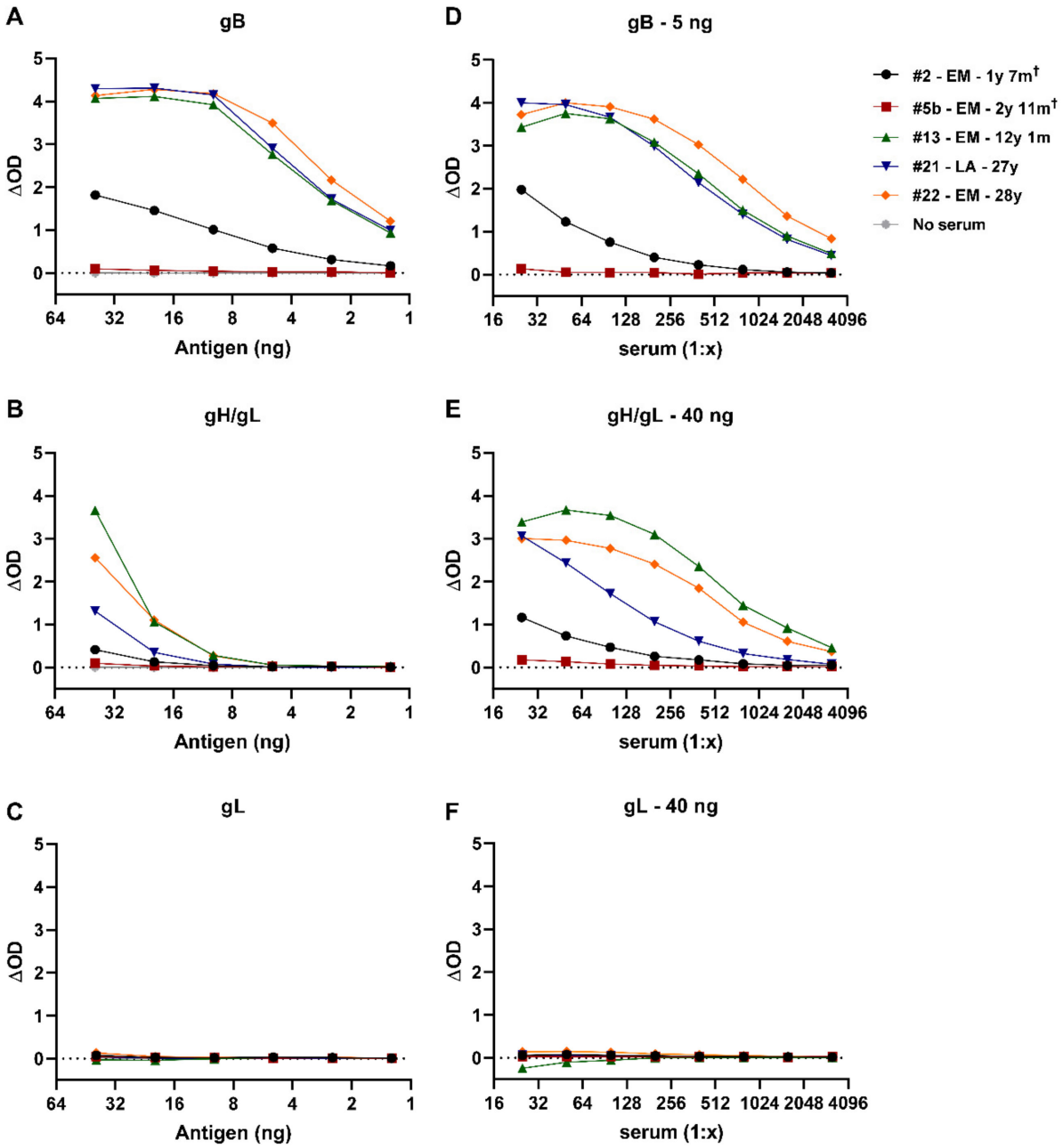

Figure 2. Antigen and serum dilution curves for the novel $\mathrm{gB}, \mathrm{gH} / \mathrm{gL}$ and $\mathrm{gL}$ ELISAs. Dilution ranges (40-1.25 ng/well) of (A) gB, (B) gH/gL, and (C) gL. (D-F) Serum dilution ranges assayed using optimal antigen dilution determined in (A-C), namely (D) $5 \mathrm{ng} \mathrm{gB},(\mathbf{E}) 40 \mathrm{ng} \mathrm{gH} / \mathrm{gL}$ and (F) $40 \mathrm{ng}$ gL. Dilution ranges were performed either single or in duplo, and results were depicted as the $\triangle O D$ (signal in antigen-coated well-signal in uncoated well). Elephant sera used are indicated by elephant number, species (Asian elephant = Elephas maximus $(\mathrm{EM})$; African elephant = Loxodonta africana $(\mathrm{LA})$ ) and age. Samples indicated by a + were taken perimortem from lethal EEHV-HD cases.

\subsection{Close to All Tested Zoo Elephants Are EEHV Seropositive}

Sera of 41 elephants from European zoos were tested using the novel EEHV ELISAs. The sample set included 28 single sera, seven longitudinal, and one paired serum samples from Asian elephants, and five single sera from African elephants. Ages at time of sampling ranged from 1 year and 4 months to 56 years for the Asian elephants and from 27 to 36 years for the African elephants. Figure 3A shows the results of the gB ELISA, sorted on elephant age. All elephants but one were found to have gB-specific antibodies, and all subadult and adult animals displayed high $\triangle O D$ levels (range: 2.0-4.2). Sera of six (of seven) juvenile Asian elephants showed a clear response towards $\mathrm{gB}$, yet for most juveniles the $\Delta \mathrm{OD}$ values were substantially lower than values obtained for the (sub)adult animals (range for positive animals: 0.6-4.2). Notably, sera of the three juvenile elephants sampled close to the time of death due to EEHV-HD showed low (\#2 and \#6) or non-detectable (\#5) gB-specific antibody levels. 
A

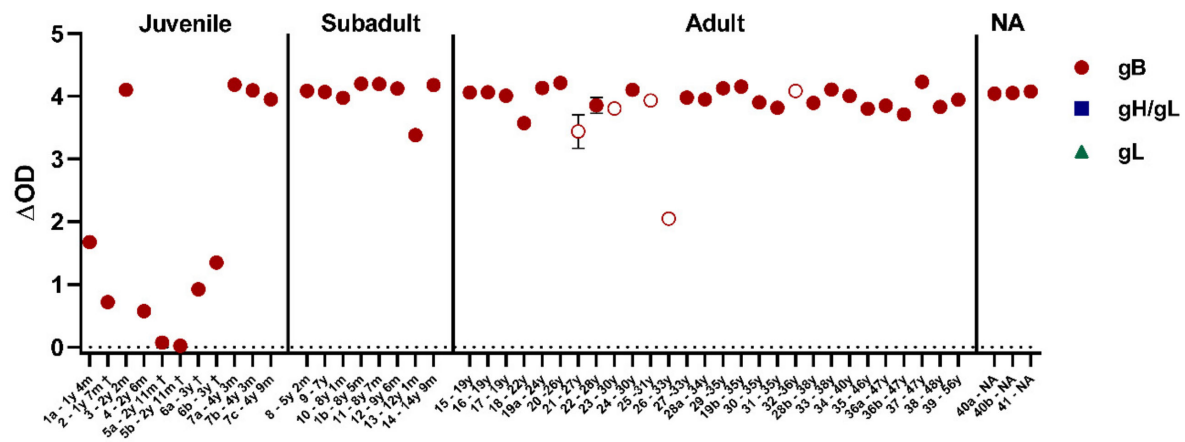

Elephant \# and age

B

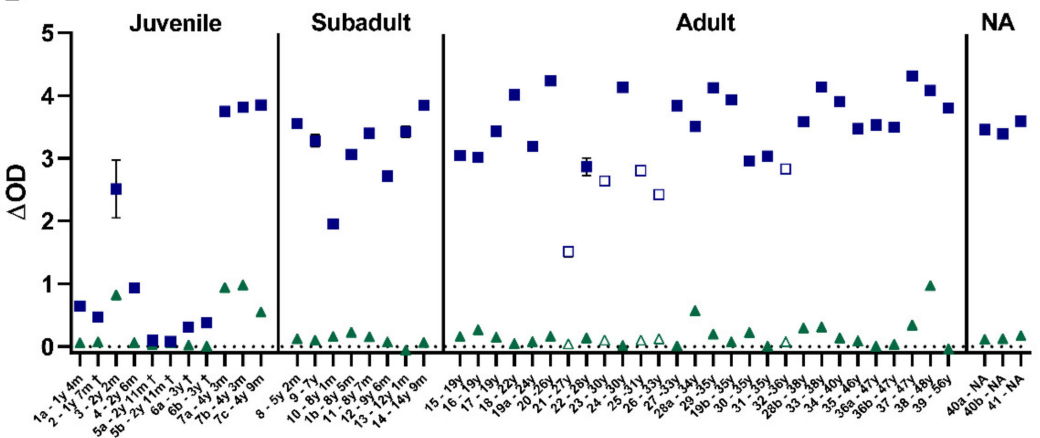

Elephant \# and age

C

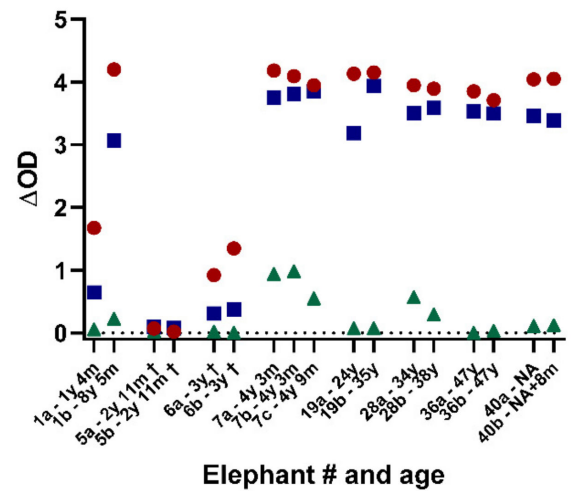

D

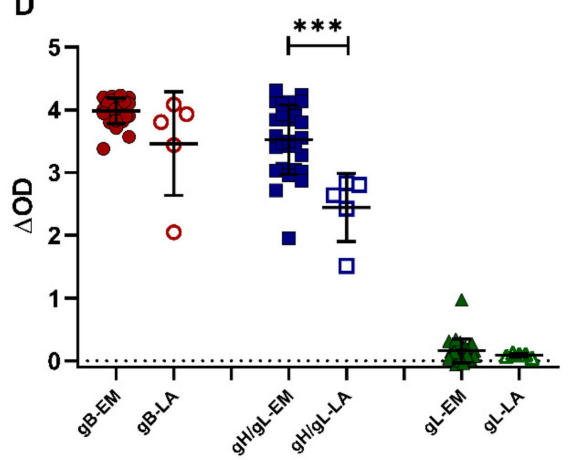

Figure 3. Assessment of EEHV seropositivity in elephants living in European zoos. $\triangle \mathrm{OD}$ values of 50 elephant sera from 41 individual elephants obtained in the gB (A), $\mathrm{gH} / \mathrm{gL}((\mathbf{B})$-blue squares) and gL ((B) — green triangles) ELISAs. Sera are identified by elephant number and age and ordered based on age at time of sampling on the $x$-axis. Longitudinal or paired samples of individual elephants are identified by the individual elephant number followed by a character (either $a, b$, or c). Samples from Asian elephants (Elephas maximus = EM) are shown by closed symbols and those from African elephants (Loxodonta Africana = LA) by open symbols. Samples indicated by a t were taken perimortem from lethal EEHV-HD cases. The majority of samples were tested once, while $8(\mathrm{gB}), 10(\mathrm{gH} / \mathrm{gL})$, and 4 (gL) sera were assayed multiple times (range 2- 10 times) with comparable results. For these samples, standard deviations are indicated, which are only visible when they exceed the size of the symbol used. (C) $\Delta O D$ values of the longitudinal or paired serum samples of eight individual elephants. (D) $\triangle \mathrm{OD}$ values of individual (sub)adult elephants divided by elephant species. For elephants with longitudinal samples available, the serum of the last sampling date was selected for analysis. Significance was tested by Mann-Whitney-test using Graphpad Prism: $* * *=p \leq 0.001$. OD $=$ optical density 
When the same serum set was tested in the gH/gL ELISA, comparable results were obtained (Figure 3B, blue squares). All elephants, except the one juvenile elephant, were seropositive for the antigen, and $\triangle \mathrm{OD}$ values were generally higher in (sub)adult animals (range: 1.5-4.3) than in the juvenile animals (range for positive animals: 0.3-3.8). Again, $\mathrm{gH} / \mathrm{gL}$-specific antibody levels in the juveniles that succumbed to EEHV-HD were low (\#2 and \#6) or non-detectable (\#5). Finally, sera from all animals were tested in the gL ELISA (Figure 2B, green triangles). In line with the results during ELISA optimization, most animals were unreactive towards gL. Nevertheless, a low but specific response was noted for some animals.

The $\Delta \mathrm{OD}$ values of the eight elephants for which longitudinal or paired samples were available (all included in Figure 3A as well) are shown in Figure 3C once more. Notably, a clear increase in $\triangle \mathrm{OD}$ values against both $\mathrm{gB}$ and $\mathrm{gH} / \mathrm{gL}$ was observed for animal \#1, which was 1 year and 4 months old at first sampling and over eight years old at second sampling. Also, for animal \#19, titers against gH/gL clearly increased during the 11 year sample interval, while titers against gB remained at similar (high) levels. For the other animals, $\triangle \mathrm{OD}$ values remained relatively stable between samples, most likely as a result of the high reactivity already observed at first sampling (animal \#7, 28, 36, and 40) and short term sampling intervals (animal \#6). For animal \#5 two different sample types (heparin and EDTA plasma), both collected directly post mortem, showed comparable results.

The above results show that the novel $\mathrm{gB}$ and $\mathrm{gH} / \mathrm{gL}$ ELISAs identify the same animals as EEHV seropositive. Nevertheless, it was noted that the $\triangle \mathrm{OD}$ values obtained in the $\mathrm{gH} / \mathrm{gL}$ ELISA (Figure 3B) were much more variable between animals than the values obtained in the gB ELISA (Figure 3A). Comparison of the $\triangle \mathrm{OD}$ values obtained for Asian and African elephants revealed a significant difference in the $\mathrm{gH} / \mathrm{gL}$, but not in the $\mathrm{gB}$ ELISA (Figure 3D).

\subsection{Comparison of the Novel $g B$ ELISA to the Previously Published EEHV $g B$ ELISA}

The performance of the novel EEHV-specific gB ELISA was compared with that of a previously published EEHV-specific gB ELISA [12]. Differences between both assays include the method through which the $\mathrm{gB}$ antigen is produced: in casu gB produced in mammalian cells or in E. coli respectively.

A randomly selected subset of sera from the European zoo cohort (20 sera from 17 Asian elephants and one serum from an African elephant) were assayed by us in both ELISAs. The $\triangle \mathrm{OD}$ values are shown in Figure $4 \mathrm{~A}$. Sera that gave rise to the highest $\Delta \mathrm{OD}$ levels in the previously published 'bacterial' gB ELISA, showed relatively low $\triangle \mathrm{OD}$ levels in the novel 'mammalian' gB ELISA. Vice versa, for many sera that tested highly positive in the 'mammalian' gB ELISA, $\triangle \mathrm{OD}$ values around 0.0 were obtained in the 'bacterial' $\mathrm{gB}$ ELISA. Results obtained by both ELISAs were found to be negatively correlated with an $R^{2}$-value of 0.42 (Figure $4 B$ ).

Since seropositivity in the 'bacterial' gB ELISA is determined based on the signal/ background-ratio instead of the $\triangle \mathrm{OD}$ values [12], signal/background-ratios were calculated for both ELISAs and plotted in Figure 4C. In line with previous publications, ratios above 3 were considered positive, ratios between 2 and 3 were considered borderline and ratios below 2 were determined to be negative $[12,13]$. By use of this cut-off all samples tested in the 'mammalian' gB ELISA were found seropositive for EEHV, while 6/21 (29\%) and 2/21 $(10 \%)$ of the samples were found to be either positive or borderline in the 'bacterial' $\mathrm{gB}$ ELISA, respectively. Also for these calculated ratios a negative correlation was observed between both ELISAs, albeit less significant and with a lower $R^{2}$ value (Figure $4 D$ ). 
A

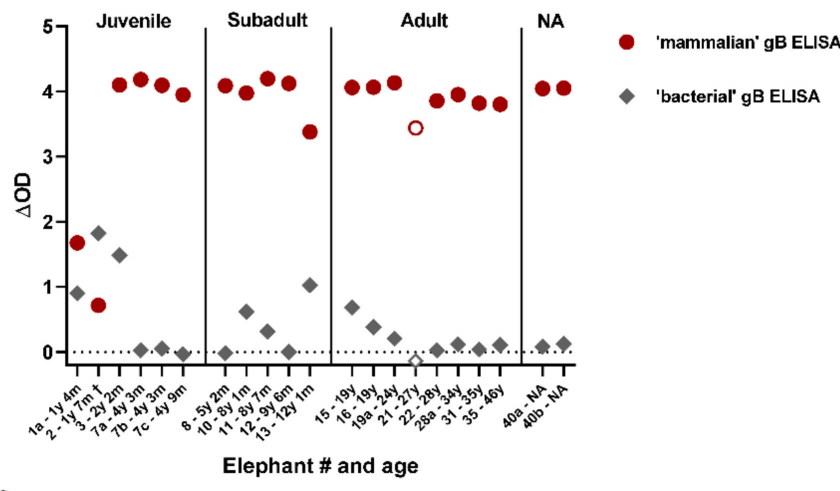

C

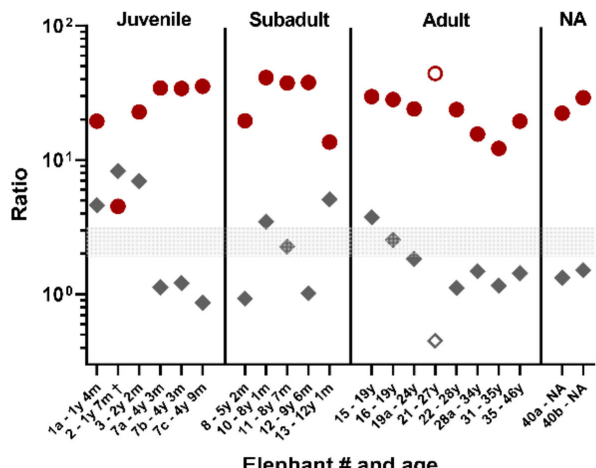

B

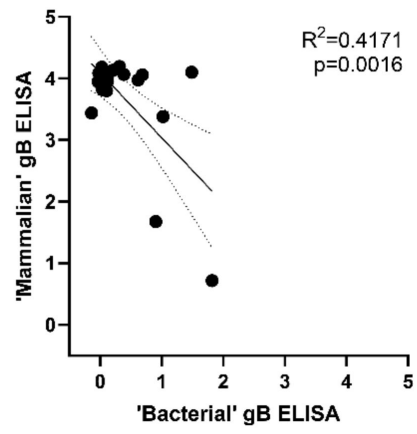

D

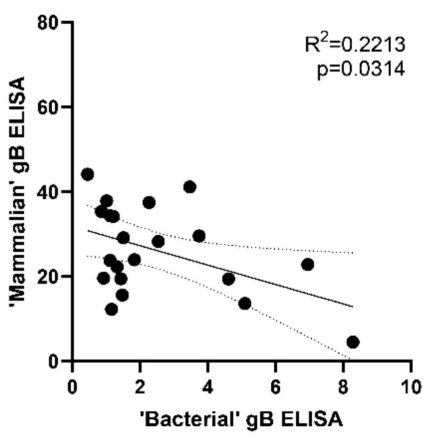

Figure 4. Comparison of the novel 'mammalian' gB ELISA to the 'bacterial' gB ELISA. (A) $\triangle \mathrm{OD}$ values of 21 sera (of 18 individual elephants) tested using both the novel 'mammalian' gB ELISA (red circles) and a previously published 'bacterial' gB ELISA (grey diamonds) [12]. Closed symbols indicate Asian elephants (EM, $n=17)$ while open symbols African elephants (LA, $n=1)$. Samples indicated by a + were taken perimortem from lethal EEHV-HD cases. Sera were tested at both 1:100 and 1:200 dilutions in the 'bacterial' gB ELISA; the most optimal (highest) $\triangle O D$ ratio is shown. (B) Correlation between the $\triangle \mathrm{OD}$ values of the 'mammalian' and 'bacterial' gB ELISA shown in (A). (C) Antigen-specific OD/background OD-ratio calculated for ELISAs. Sera were tested at both 1:100 and 1:200 dilutions in the bacterial gB ELISA; the most optimal (highest) $\triangle O D$ ratio is shown. Symbols as described in (A). (D) Correlation between the antigen-specific OD/background OD-ratio's shown in (C). Correlations were analyzed using GraphPad Prism.

3.5. Antisera Generated against Linear gB Epitopes Suggest Altered Epitope Availability in gB Produced in Bacterial versus Mammalian Cells

A likely explanation for the observed differences between the 'bacterial' and 'mammalian' gB ELISAs would be different epitope availability between both recombinant gB proteins. To explore this hypothesis, rabbit sera generated against five different gB-specific peptides (Figure 5A) were assessed for their abilities to recognize the mammalian and bacterial $\mathrm{gB}$ antigens in ELISA. In agreement with our hypothesis, differential recognition was indeed observed for the peptide-specific rabbit sera (Figure 5B). Mammalian-produced gB was best recognized by the serum generated against peptide 5 , whereas bacterial-produced gB was primarily recognized by sera generated against peptides 1 and 4 . For peptide 4 it must be noted that its epitope, which spans the furin cleavage site, was partially mutated in the 'mammalian' $\mathrm{gB}$ construct. 
A

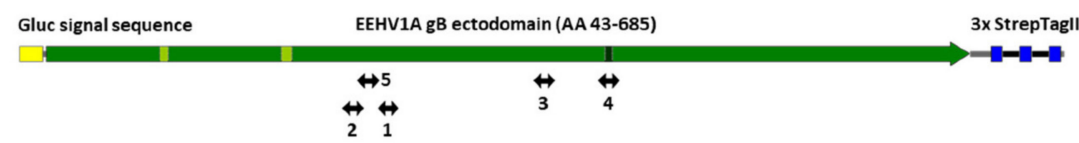

B

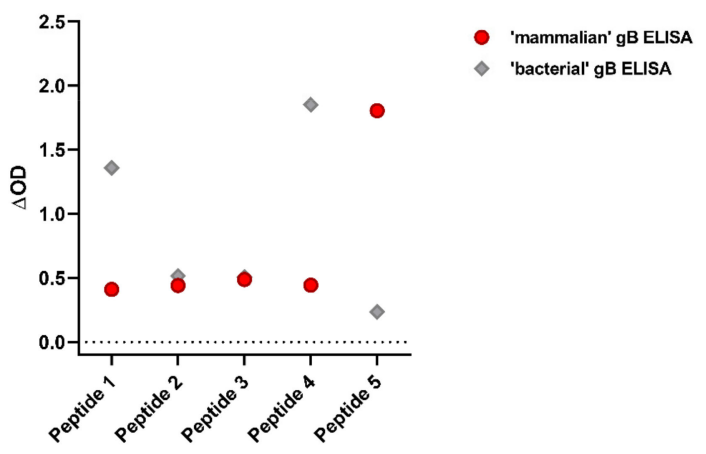

Figure 5. Reactivity of five EEHV1A gB peptide-specific rabbit antisera towards mammalian and bacterial produced gB. (A) Positions of the five gB peptides to which rabbit antisera were generated are indicated [12]. (B) $\triangle O D$ values for the $g B$ peptide-specific rabbit sera measured in the mammalian $\mathrm{gB}$ (red circles) and bacterial gB (grey diamonds) ELISAs. Sera were tested at least once in duplicate at a 1:100 dilution. Representative results are shown.

\subsection{All Tested Laotian Elephants under Human Care Are Seropositive for EEHV}

After having shown that nearly all elephants in European zoos tested EEHV seropositive, we aimed to explore the EEHV status of Asian elephants living in range countries. Sera from 69 elephants could be included for analysis, and all were found to be seropositive for EEHV, with $\triangle \mathrm{OD}$ values ranging between 3.2-4.3 and 2.2-4.2 for gB and gH/gL, respectively (Figure 6). We conclude that all the Laotian elephants tested are infected with one or multiple EEHV types.

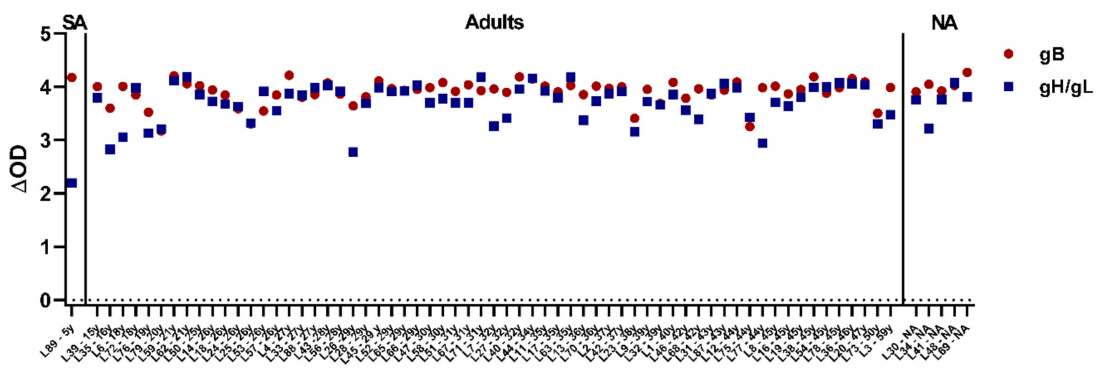

Figure 6. Results obtained in the $\mathrm{gB}$ and $\mathrm{gH} / \mathrm{gL}$ ELISAs for 69 serum samples from individual Asian elephants living under human care in Laos. Samples are plotted based on age at sampling. $\mathrm{SA}=$ subadult, $\mathrm{NA}=$ information on age not available.

\section{Discussion}

This study aimed at improving diagnostic tools for EEHV infection in elephants and obtaining novel insights into the spread of EEHV among elephants. Since the virus cannot be propagated in vitro, one of the major problems is availability of EEHV-specific antigens. Here, we report the successful production and purification of recombinant EEHV1A gB and $\mathrm{gH} / \mathrm{gL}$, and the subsequent development of EEHV glycoprotein-specific ELISAs. The novel ELISAs showed that 40 out of 41 screened elephants from European zoos were EEHV seropositive, and all 69 screened (semi-)captive elephants from Laos, one of the Asian elephant range countries.

The prevalence of EEHV positive animals in both cohorts included in this study was considerably higher than that previously reported in two other serosurveys [12,13]. In 
2015, Van den Doel and coworkers showed that 37\% of the European zoo elephants tested $(n=125)$ were seropositive to EEHV [12], while in 2019 Angkawanish and coworkers reported that $42 \%$ of 994 Thai elephants living under human care were EEHV seropositive [13]. Both serosurveys used the 'bacterial' gB ELISA, of which this study showed that it underestimates EEHV seropositivity as compared to the novel ELISAs (Figure 4). This difference may be best explained by incorrect folding of E. coli-expressed gB due to a lack of mammalian-type glycosylation [34]. Differential reactivity of antisera raised against a set of linear gB peptides is in agreement herewith (Figure 5). Of the different peptide sera, the serum raised against peptide 5 recognized gB expressed in mammalian cells most clearly. A similar peptide 5 antiserum was recently successfully used to detect EEHV-infected cells [35]. The fact that the same animals in this study were identified as EEHV seropositive by use of two different EEHV antigens, gB and gH/gL, while most animals were unreactive to a third EEHV antigen ( $\mathrm{gL})$, produced in the same manner and carrying the same protein tag as $\mathrm{gB}$ and $\mathrm{gH} / \mathrm{gL}$, further supported the validity of our results and excluded the possibility of non-specific binding to either the tag or possible contaminants introduced during protein production.

All (sub)adult Asian $(n=98)$ and African $(n=5)$ elephants tested in this study, including a large cohort from Laos $(n=69)$, were seropositive to EEHV. High seroprevalence has been reported for many herpesvirus infections [36], however for EEHV similar seroprevalence $(82 \%)$ has thus far only been reported for a relatively small number of elephants $(n=24)$, living in four different North American zoos, of which all adult elephants $(n=10)$ were EEHV seropositive [8]. In line herewith, two studies that monitored EEHV shedding in a limited number of animals in two zoo herds for several months, showed that $72 \%$ ( $n=7$ [37]) to $100 \%(n=6$ [7]) of the elephants tested were infected with EEHV. Our study indicates that EEHV is widespread among Asian, and possibly also African elephants, both in zoos and in a range country (Laos) with potentially all adult animals infected with one or more EEHV subtypes. More studies are needed to establish whether this also holds true for free-ranging elephants.

In line with antibody responses to many human herpesvirus infections [17-20], both $\mathrm{gB}$ and $\mathrm{gH} / \mathrm{gL}$ were identified as important targets of the EEHV-specific immune response, while $\mathrm{gL}$, in absence of $\mathrm{gH}$, was found not to be a major target of the natural EEHV-specific immune response. Interestingly, the anti-gH/gL response was found to be more variable between elephants than responses towards $\mathrm{gB}$, which may be explained by elephants being infected with different EEHV types, and $\mathrm{gH}$ and $\mathrm{gL}$ being less conserved between the different EEHV species than gB (Table 2). In agreement herewith, anti-gB responses of Asian elephants, for which infections with EEHV subtype 1A are common, and of African elephants, which naturally carry other EEHV subtypes [38], were comparable in our ELISAs, while the responses towards $\mathrm{gH} / \mathrm{gL}$ were significantly higher in Asian than in African elephants (Figure 3D). Our data suggest that while the gB ELISA should be regarded as a pan-EEHV ELISA, gH/gL might be an interesting target for the development of subtypespecific EEHV ELISAs. The latter may be possible by comparing (end point) titers towards a set of subtype-specific $\mathrm{gH} / \mathrm{gL}$ proteins, in analogy to comparative virus neutralization tests used for serotyping (human) flavivirus and orthohantavirus infections [39,40].

Recently, Fuery and co-workers suggested that EEHV-HD was associated with a primary EEHV infection rather than virus reactivation [8]. Within our European zoo cohort, sera of three juvenile animals that succumbed to EEHV1A-HD, collected during the EEHVHD episode or directly post-mortem, were tested. EEHV-specific antibody levels in all three animals were low $(n=2)$ or undetectable $(n=1)$, which would be consistent with a primary EEHV infection rather than reactivation. This supports the hypothesis of EEHV-HD being the result of an uncontrolled primary infection. 
Table 2. Amino acid identity between $\mathrm{gB}, \mathrm{gH}$, and gL.

\begin{tabular}{|c|c|c|c|c|c|c|c|}
\hline \multirow[b]{2}{*}{ Subtype } & \multirow{2}{*}{$\begin{array}{c}\text { Associated } \\
\text { Elephant } \\
\text { Species }\end{array}$} & \multicolumn{2}{|c|}{ EEHV1A gB (AA 43-685) } & \multicolumn{2}{|c|}{ EEHV1A gH (AA 30-706) } & \multicolumn{2}{|c|}{ EEHV1A gL (AA 57-304) } \\
\hline & & $\begin{array}{l}\text { AA Identity } \\
\text { (Min-Max) }^{\text {a }}\end{array}$ & $n$ & $\begin{array}{l}\text { AA Identity } \\
\text { (Min-Max) }^{a}\end{array}$ & $n$ & $\begin{array}{l}\text { AA Identity } \\
\left(_{(M i n-M a x)^{a}}\right.\end{array}$ & $n$ \\
\hline EEHV1A & EM & $97.52-98.91 \%$ & 19 & $78.29-100.00 \%$ & 14 & $94.35-100.00 \%$ & 19 \\
\hline EEHV6 & LA & $88.84-88.99 \%$ & 2 & $84.07 \%$ & 1 & $77.96-79.18 \%$ & 2 \\
\hline EEHV1B & $\mathrm{EM}$ & $85.71-85.96 \%$ & 5 & $67.6-67.89 \%$ & 2 & $71.02 \%$ & 3 \\
\hline EEHV2 & LA & $81.71 \%$ & 1 & $59.74 \%$ & 1 & $58.06 \%$ & 2 \\
\hline EEHV5 & EM & $81.24-81.86 \%$ & 4 & $58.69 \%$ & 1 & $57.66-58.06 \%$ & 3 \\
\hline EEHV4 & EM & $67.03 \%$ & 1 & $46.04-46.27 \%$ & 2 & $37.34 \%$ & 1 \\
\hline EEHV3 & LA & NA & 0 & NA & 0 & NA & 0 \\
\hline EEHV7 & LA & NA & 0 & NA & 0 & NA & 0 \\
\hline
\end{tabular}

${ }^{a}$ Amino acid identity is indicated between sequences used in this study and the $\mathrm{gB}, \mathrm{gH}$, and gL protein sequences available for the different EEHV (sub)types in GenBank. Sequences are ordered from most homologous to least homologous to EEHV1A, showing minimal and maximal homology to the input sequence and the number $(n)$ of sequences included for analysis. Partial AA sequences (coverage $<90 \%)$ were excluded from the analysis. For EEHV species 3 and 7, no sequences were available for analysis. EM = Elephas maximus (Asian elephant); LA = Loxodonta africana (African elephant).

Albeit based on a limited number of cases, the current study also suggests that not only completely seronegative animals, but also calves with low (maternal) antibody levels are at risk of developing EEHV-HD. Future studies are needed to discern how the levels, avidity and specificity of antibodies targeting $\mathrm{gB}$ and $\mathrm{gH} / \mathrm{gL}$ are correlated with protection against severe disease, which is crucial knowledge for elephant management and future development of an effective EEHV vaccine. Pending these studies, these novel ELISAs may already be used for the detection of those young elephants that run the most risk of developing EEHV-HD. Furthermore, the relative low-tech nature of these novel ELISAs allows easy dissemination to local laboratories in Asian and African elephant range countries to determine the EEHV seroprevalence in larger cohorts of captive and, where blood access is possible, free-living elephants.

Supplementary Materials: The following are available online at https:/ / www.mdpi.com/1999-4915/ 13/2/283/s1, Figure S1: HCMV strain Merlin and EEHV1A strain Kimba gH and gL protein alignments.

Author Contributions: Conceptualization, T.E.H., W.S., V.P.M.G.R., and C.A.M.d.H.; methodology, T.E.H., V.P.M.G.R., and C.A.M.d.H.; validation, T.E.H., V.P.M.G.R., and C.A.M.d.H.; formal analysis, T.E.H.; investigation, T.E.H.; resources, W.S., G.M., P.B.v.d.D., F.M.M., A.C.-G., F.V., V.P.M.G.R., and C.A.M.d.H.; writing - original draft preparation, T.E.H., V.P.M.G.R., and C.A.M.d.H.; writingreview and editing, T.E.H., W.S., G.M., P.B.v.d.D., F.M.M., A.C.-G., F.V., V.P.M.G.R., and C.A.M.d.H.; visualization, T.E.H.; supervision, V.P.M.G.R. and C.A.M.d.H.; project administration, V.P.M.G.R. and C.A.M.d.H.; funding acquisition, T.E.H., W.S., V.P.M.G.R., and C.A.M.d.H. All authors have read and agreed to the published version of the manuscript.

Funding: We would like to thank the Royal Zoological Society of Antwerp, DierenPark Amersfoort Wildlife Fund, Abri voor Dieren Foundation, Animales Foundation, Utrecht University Fund, P. Zwart Foundation, A.A.M. Bijleveld Foundation, Marjo Hoedemaker Foundation, Named Fund Friends of VetMed, and many individual donors for their ongoing support of this research.

Institutional Review Board Statement: Ethical review and approval were waived, as this study only made use of archival elephant serum samples, which were taken (for diagnostic purposes) under routine veterinary care by (zoo) veterinary staff and which were subsequently shared with our institutes for EEHV research purposes.

Informed Consent Statement: Not Applicable.

Data Availability Statement: All relevant data generated for this paper are within the manuscript and its supporting information files.

Acknowledgments: We would like to thank all zoos involved in this study for collection and sharing of elephant serum samples. In addition, we would like to thank Jérôme Lassausaie and the staff of the Lao livestock department for sample collection from the Laotian elephants. 
Conflicts of Interest: The authors declare no conflict of interest. Funders had no role in the study design, data collection and analysis, decision to publish, or preparation of the manuscript.

\section{References}

1. Howard, L.; Schaftenaar, W. Elephant Endotheliotropic Herpesvirus. In Fowler's Zoo and Wild Animal Medicine Current Therapy; Elsevier: Saunders, PA, USA, 2018; Volume 9.

2. Jeffrey, A.; Evans, T.S.; Molter, C.; Howard, L.L.; Ling, P.; Goldstein, T.; Gilardi, K. Noninvasive sampling for detection of elephant endotheliotropic herpesvirus and genomic DNA in Asian (Elephas maximus) and African (Loxodonta africana) elephants. J. Zoo Wildl. Med. 2020, 51, 433-437. [CrossRef]

3. Long, S.Y.; Latimer, E.M.; Hayward, G.S. Review of Elephant Endotheliotropic Herpesviruses and Acute Hemorrhagic Disease. ILAR J. 2016, 56, 283-296. [CrossRef] [PubMed]

4. Boonprasert, K.; Punyapornwithaya, V.; Tankaew, P.; Angkawanish, T.; Sriphiboon, S.; Titharam, C.; Brown, J.L.; Somgird, C. Survival analysis of confirmed elephant endotheliotropic herpes virus cases in Thailand from 2006-2018. PLOS ONE 2019, 14, e0219288. [CrossRef] [PubMed]

5. Mahato, G.; Sarma, K.K.; Pathak, D.C.; Barman, N.N.; Gogoi, P.; Dutta, M.; Basumatary, P. Endotheliotropic herpesvirus infection in Asian elephants (Elephas maximus) of Assam, India. Vet. World 2019, 12, 1790-1796. [CrossRef]

6. Oo, Z.M.; Aung, Y.H.; Aung, T.T.; San, N.; Tun, Z.M.; Hayward, G.S.; Zachariah, A. Elephant Endotheliotropic Herpesvirus Hemorrhagic Disease in Asian Elephant Calves in Logging Camps, Myanmar. Emerg. Infect. Dis. 2020, 26, 63-69. [CrossRef] [PubMed]

7. Hardman, K.; Dastjerdi, A.; Gurrala, R.; Routh, A.; Banks, M.; Steinbach, F.; Bouts, T. Detection of elephant endotheliotropic herpesvirus type 1 in asymptomatic elephants using TaqMan real-time PCR. Vet. Rec. 2012, 170, 205. [CrossRef]

8. Fuery, A.; Pursell, T.; Tan, J.; Peng, R.; Burbelo, P.D.; Hayward, G.S.; Ling, P.D. Lethal Hemorrhagic Disease and Clinical Illness Associated with Elephant Endotheliotropic Herpesvirus 1 Are Caused by Primary Infection: Implications for the Detection of Diagnostic Proteins. J. Virol. 2020, 94, e01528-19. [CrossRef]

9. Sripiboon, S.; Ditcham, W.; Vaughan-Higgins, R.; Jackson, B.; Robertson, I.; Thitaram, C.; Angkawanish, T.; Phatthanakunanan, S.; Lertwatcharasarakul, P.; Warren, K. Subclinical infection of captive Asian elephants (Elephas maximus) in Thailand with elephant endotheliotropic herpesvirus. Arch. Virol. 2020, 165, 397-401. [CrossRef]

10. AsERSM. Asian elephant range states meeting (AsERSM) final report, 2017. In Proceedings of the AsERSM, Jakarta, Indonesia, 18-20 April 2017.

11. Wald, A.; Corey, L. Persistence in the population: Epidemiology, transmission. In Human Herpesviruses: Biology, Therapy, and Immunoprophylaxis; Arvin, A., Campadelli-Fiume, G., Mocarski, E., Moore, P.S., Roizman, B., Whitley, R., Yamanishi, K., Eds.; Cambridge University Press: Cambridge, UK, 2007.

12. van den Doel, P.B.; Prieto, V.R.; van Rossum-Fikkert, S.E.; Schaftenaar, W.; Latimer, E.; Howard, L.; Chapman, S.; Masters, N.; Osterhaus, A.D.; Ling, P.D.; et al. A novel antigen capture ELISA for the specific detection of IgG antibodies to elephant endotheliotropic herpes virus. BMC Vet. Res. 2015, 11, 203. [CrossRef]

13. Angkawanish, T.; Nielen, M.; Vernooij, H.; Brown, J.L.; Van Kooten, P.J.S.; Doel, P.B.V.D.; Schaftenaar, W.; Na Lampang, K.; Rutten, V.P.M.G. Evidence of high EEHV antibody seroprevalence and spatial variation among captive Asian elephants (Elephas maximus) in Thailand. Virol. J. 2019, 16, 33. [CrossRef]

14. Heldwein, E.E.; Lou, H.; Bender, F.C.; Cohen, G.H.; Eisenberg, R.J.; Harrison, S.C. Crystal structure of glycoprotein B from herpes simplex virus 1. Science 2006, 313, 217-220. [CrossRef]

15. Eisenberg, R.J.; Atanasiu, D.; Cairns, T.M.; Gallagher, J.R.; Krummenacher, C.; Cohen, G.H. Herpes Virus Fusion and Entry: A Story with Many Characters. Viruses 2012, 4, 800-832. [CrossRef]

16. Cooper, R.S.; Heldwein, E.E. Herpesvirus gB: A Finely Tuned Fusion Machine. Viruses 2015, 7, 6552-6569. [CrossRef] [PubMed]

17. Cairns, T.M.; Huang, Z.-Y.; Whitbeck, J.C.; De Leon, M.P.; Lou, H.; Wald, A.; Krummenacher, C.; Eisenberg, R.J.; Cohen, G.H. Dissection of the Antibody Response against Herpes Simplex Virus Glycoproteins in Naturally Infected Humans. J. Virol. 2014, 88, 12612-12622. [CrossRef] [PubMed]

18. Schoppel, K.; Kropff, B.; Schmidt, C.; Vornhagen, R.; Mach, M. The humoral immune response against human cytomegalovirus is characterized by a delayed synthesis of glycoprotein-specific antibodies. J. Infect. Dis. 1997, 175, 533-544. [CrossRef] [PubMed]

19. Urban, M.; Klein, M.; Britt, W.J.; Hassfurther, E.; Mach, M. Glycoprotein H of human cytomegalovirus is a major antigen for the neutralizing humoral immune response. J. Gen. Virol. 1996, 77 Pt 7, 1537-1547. [CrossRef]

20. Bu, W.; Joyce, M.G.; Nguyen, H.; Banh, D.V.; Aguilar, F.; Tariq, Z.; Yap, M.L.; Tsujimura, Y.; Gillespie, R.A.; Tsybovsky, Y.; et al. Immunization with Components of the Viral Fusion Apparatus Elicits Antibodies That Neutralize Epstein-Barr Virus in B Cells and Epithelial Cells. Immunity 2019, 50, 1305-1316.e6. [CrossRef] [PubMed]

21. de Vries, R.P.; de Vries, E.; Bosch, B.J.; de Groot, R.J.; Rottier, P.J.; de Haan, C.A. The influenza A virus hemagglutinin glycosylation state affects receptor-binding specificity. Virology 2010, 403, 17-25. [CrossRef]

22. de Vries, R.P.; de Vries, E.; Moore, K.S.; Rigter, A.; Rottier, P.J.; de Haan, C.A. Only two residues are responsible for the dramatic difference in receptor binding between swine and new pandemic H1 hemagglutinin. J. Biol. Chem. 2011, 286, 5868-5875. [CrossRef] 
23. Lassausaie, J.; Bret, A.; Bouapao, X.; Chanthavong, V.; Castonguay-Vanier, J.; Quet, F.; Mikota, S.K.; Théorêt, C.; Buisson, Y.; Bouchard, B. Tuberculosis in Laos, who is at risk: The mahouts or their elephants? Epidemiology Infect. 2014, 143, $922-931$. [CrossRef] [PubMed]

24. Arivazhagan, C.; Sukumar, R. Constructing age structures of Asian elephant populations: A comparison of two field methods of age estimation. Gajah 2008, 29, 11-16.

25. Humphreys, A.F.; Tan, J.; Peng, R.; Benton, S.M.; Qin, X.; Worley, K.C.; Mikulski, R.L.; Chow, D.C.; Palzkill, T.G.; Ling, P.D. Generation and characterization of antibodies against Asian elephant (Elephas maximus) IgG, IgM, and IgA. PLoS ONE 2015, 10, e0116318. [CrossRef]

26. Paungpin, W.; Wiriyarat, W.; Chaichoun, K.; Tiyanun, E.; Sangkachai, N.; Changsom, D.; Poltep, K.; Ratanakorn, P.; Puthavathana, P. Serosurveillance for pandemic influenza A (H1N1) 2009 virus infection in domestic elephants, Thailand. PLoS ONE 2017, 12, e0186962. [CrossRef] [PubMed]

27. Hutchinson, L.; Browne, H.; Wargent, V.; Davis-Poynter, N.; Primorac, S.; Goldsmith, K.; Minson, A.C.; Johnson, D.C. A novel herpes simplex virus glycoprotein, $\mathrm{gL}$, forms a complex with glycoprotein $\mathrm{H}(\mathrm{gH})$ and affects normal folding and surface expression of gH. J. Virol. 1992, 66, 2240-2250. [CrossRef] [PubMed]

28. Peng, T.; Ponce-de-Leon, M.; Jiang, H.; Dubin, G.; Lubinski, J.M.; Eisenberg, R.J.; Cohen, G.H. The gH-gL complex of herpes simplex virus (HSV) stimulates neutralizing antibody and protects mice against HSV type 1 challenge. J. Virol. 1998, $72,65-72$. [CrossRef]

29. Klyachkin, Y.M.; Stoops, K.D.; Geraghty, R.J. Herpes simplex virus type 1 glycoprotein L mutants that fail to promote trafficking of glycoprotein $\mathrm{H}$ and fail to function in fusion can induce binding of glycoprotein L-dependent anti-glycoprotein $\mathrm{H}$ antibodies. $J$. Gen. Virol. 2006, 87, 759-767. [CrossRef]

30. Gardner, T.J.; Hernandez, R.E.; Noriega, V.M.; Tortorella, D. Human cytomegalovirus gH stability and trafficking are regulated by ER-associated degradation and transmembrane architecture. Sci. Rep. 2016, 6, 23692. [CrossRef]

31. Gasteiger, E.; Gattiker, A.; Hoogland, C.; Ivanyi, I.; Appel, R.D.; Bairoch, A. ExPASy: the proteomics server for in-depth protein knowledge and analysis. Nucleic Acids Res. 31:3784-3788(2003). Nucleic Acids Res. 2003, 31, 3784-3788. [CrossRef]

32. Gupta, R.; Jung, E.; Brunak, S. NetNGlyc 1.0 Server-Prediction of N-glycosylation Sites in Human Proteins. Available online: http://www.cbs.dtudk/services/NetNGlyc/.

33. Ciferri, C.; Chandramouli, S.; Donnarumma, D.; Nikitin, P.A.; Cianfrocco, M.A.; Gerrein, R.; Feire, A.L.; Barnett, S.W.; Lilja, A.E.; Rappuoli, R.; et al. Structural and biochemical studies of HCMV gH/gL/gO and Pentamer reveal mutually exclusive cell entry complexes. Proc. Natl. Acad. Sci. USA 2015, 112, 1767-1772. [CrossRef]

34. Xu, C.; Ng, D.T.W. Glycosylation-directed quality control of protein folding. Nat. Rev. Mol. Cell Biol. 2015, 16, 742-752. [CrossRef] [PubMed]

35. Kochagul, V.; Srivorakul, S.; Boonsri, K.; Somgird, C.; Sthitmatee, N.; Thitaram, C.; Pringproa, K. Production of antibody against elephant endotheliotropic herpesvirus (EEHV) unveils tissue tropisms and routes of viral transmission in EEHV-infected Asian elephants. Sci. Rep. 2018, 8, 4675. [CrossRef] [PubMed]

36. Olsson, J.; Kok, E.; Adolfsson, R.; Lövheim, H.; Elgh, F. Herpes virus seroepidemiology in the adult Swedish population. Immun. Ageing 2017, 14, 10. [CrossRef]

37. Ackermann, M.; Hatt, J.-M.; Schetle, N.; Steinmetz, H. Identification of shedders of elephant endotheliotropic herpesviruses among Asian elephants (Elephas maximus) in Switzerland. PLoS ONE 2017, 12, e0176891. [CrossRef] [PubMed]

38. Zachariah, A.; Sajesh, P.K.; Santhosh, S.; Bathrachalam, C.; Megha, M.; Pandiyan, J.; Jishnu, M.; Kobragade, R.S.; Long, S.Y.; Zong, J.-C.; et al. Extended genotypic evaluation and comparison of twenty-two cases of lethal EEHV1 hemorrhagic disease in wild and captive Asian elephants in India. PLoS ONE 2018, 13, e0202438. [CrossRef] [PubMed]

39. Roehrig, J.T.; Hombach, J.; Barrett, A.D. Guidelines for Plaque-Reduction Neutralization Testing of Human Antibodies to Dengue Viruses. Viral Immunol. 2008, 21, 123-132. [CrossRef] [PubMed]

40. Lundkvist, Å.; Vapalahti, O.; Henttonen, H.; Vaheri, A.; Plyusnin, A. Hantavirus infections among mammalogists studied by focus reduction neutralisation test. Eur. J. Clin. Microbiol. Infect. Dis. 2000, 19, 802-803. [CrossRef] [PubMed] 